\title{
TRADUÇÃO E ADAPTAÇÃO CULTURAL PARA O PORTUGUÊS DO INSTRUMENTO "THE BOWEL DISEASE QUESTIONNAIRE", UTILIZADO PARA A AVALIAÇÃO DE DOENÇAS GASTROINTESTINAIS FUNCIONAIS
}

\author{
Mariana Tschoepke AIRES ${ }^{2,3}$ e Guilherme Loureiro WERNECK ${ }^{1,3}$
}

RESUMO - Racional - As doenças gastrointestinais funcionais são reconhecidas como um problema de saúde pública e sua prevalência é pouco estudada no nosso meio. Em 1989, pesquisadores da Mayo Clinic elaboraram e validaram um questionário para a avaliação das doenças gastrointestinais funcionais denominado "The Bowel Disease Questionnaire". Apesar de ter sido utilizado em diferentes populações, sua aplicação em um contexto sociocultural diferente daquele para o qual foi desenvolvido, necessita de prévia adaptação para garantir a qualidade das informações a serem captadas. Objetivo - Realizar a tradução e a adaptação cultural do "The Bowel Disease Questionnaire" para o português com a finalidade de aplicação a uma população de adolescentes do Rio de Janeiro. Métodos - Foram avaliadas as equivalências conceitual e de itens através de revisão bibliográfica e de reuniões com especialistas. A avaliação da igualdade semântica constou de julgamento acerca das equivalências de significado referencial e geral entre a retradução e o original e entre esta e a edição em português, respectivamente. A equivalência de mensuração foi avaliada através da confiabilidade e da consistência interna. Resultados - Os conceitos abarcados pelo questionário original foram considerados pertinentes no nosso meio. O significado geral e referencial das palavras/termos se manteve na maioria das questões. A confiabilidade variou de razoável a quase perfeita, enquanto os grupos de questões referentes às doenças gastrointestinais funcionais mostraram consistência interna variando de 0,66 a 0,74. Conclusão - A versão em português do "The Bowel Disease Questionnaire" parece ser semântica e de conceito equivalente ao original e avaliar adequadamente as doenças gastrointestinais funcionais. O instrumento resultante da adaptação pode ser útil para avaliar as doenças gastrointestinais funcionais em populações de adolescentes no contexto brasileiro.

DESCRITORES - Enteropatias. Doenças funcionais do cólon. Dispepsia. Saúde do adolescente. Questionários. Validade.

\section{INTRODUÇÃO}

As doenças gastrointestinais funcionais (DGF) configuram um grupo de condições caracterizado por sintomas gastrointestinais crônicos que não podem ser explicados por alterações estruturais ou bioquímicas passíveis de identificação pelos testes atualmente disponíveis ${ }^{(6,8)}$. Tradicionalmente, essas doenças eram consideradas como diagnóstico de exclusão, entretanto, as duas últimas décadas foram marcadas pela realização de diversos estudos voltados para a caracterização dessas doenças, com vistas a contribuir para a elaboração de um diagnóstico positivo das doenças funcionais ${ }^{(15,27)}$.

Atualmente, as DGF são classificadas de acordo com os critérios de Roma ${ }^{(12)}$, que permitiram a caracterização de um perfil para as mesmas e asseguraram aos pacientes

Trabalho realizado no Núcleo de Estudos de Saúde Coletiva, Universidade Federal do Rio de Janeiro

${ }^{1}$ Núcleo de Estudos de Saúde Coletiva, Universidade Federal do Rio de Janeiro (UFRJ); ${ }^{2}$ Instituto de Puericultura e Pediatria Martagão Gesteira, UFRJ; ${ }^{3}$ Instituto de Medicina Social, Universidade do Estado do Rio de Janeiro, RJ.

Endereço para correspondência: Dra. Mariana T. Aires - Av. Ataulfo de Paiva, 255 - apt.801 - Leblon -22440-032-Rio de Janeiro, RJ. E-mail: marianataires@gmail.com 
que eles apresentam uma doença real e não apenas sintomas que resultam em investigações de resultados negativos ${ }^{(11)}$. Sob a luz da epidemiologia, a classificação tornou mais comparáveis os estudos que adotam essas definições ${ }^{(36)}$.

Essas doenças apresentam-se como importante problema de saúde pública por sua alta prevalência na população, sendo também responsáveis pela maior parte das queixas dos pacientes avaliados em clínicas e ambulatórios de gastroenterologia, além de interferir na qualidade de vida ${ }^{(1,4,10,13,16,18,22,26,34,36,44,47)} \mathrm{e}$ resultar em aumento de custos para o sistema de saúde ${ }^{(43,45)}$.

Grande problema para a abordagem epidemiológica das doenças funcionais reside no fato de que essas não são caracterizadas por anormalidades objetivas mensuráveis, fazendo com que sua classificação seja baseada na sintomatologia ${ }^{(12)}$.

TALLEY et al. ${ }^{(38)}$, em 1989, desenvolveram um instrumento capaz de diferenciar três grandes grupos de indivíduos: a) pacientes com doenças funcionais, em particular a dispepsia funcional e a síndrome do intestino irritável, b) pacientes com doenças orgânicas e c) indivíduos saudáveis. $\mathrm{O}$ instrumento desenvolvido foi um questionário auto-aplicável que contempla uma série de sintomas gastrointestinais relevantes para a identificação de doenças funcionais, denominado "The Bowel Disease Questionnaire" (BDQ), previamente validado e que passou a ser amplamente utilizado em estudos de base populacional entre idosos, adultos e adolescentes ${ }^{(2,3,14,23,24,25,33,38,39,40,41,42,46)}$.

\section{LITERATURA}

Em epidemiologia, é crescente o interesse por questionários previamente validados para mensurar fatores de risco para doenças e agravos à saúde, exposições de interesse e desfechos multidimensionais, como a qualidade de $v_{i d a}{ }^{(5,32)}$. Entretanto, nem sempre estão disponíveis em determinado contexto sociocultural instrumentos válidos para a aferição dos diversos aspectos ligados à saúde e à qualidade de vida. De acordo com GUILLEMIN et al. ${ }^{(17)}$, para enfrentar este problema há duas opções: desenvolver novo instrumento de aferição para ser aplicado na cultura alvo ou utilizar instrumento previamente desenvolvido em outra cultura. Entretanto, para a utilização de questionários validados em outras culturas, torna-se necessária uma abordagem sistemática do processo de tradução e adaptação transcultural destes instrumentos ${ }^{(17)}$.

HERDMAN et al. ${ }^{(19)}$ propõem um roteiro de investigação que envolve seis subtipos de equivalência, que devem ser sistematicamente considerados no processo de tradução e adaptação de um questionário: a) equivalência conceitual, b) equivalência de itens, c) equivalência semântica, d) equivalência operacional, e) equivalência de mensuração e f) equivalência funcional. Com base nesta proposição, o presente trabalho descreve os resultados da tradução e adaptação transcultural do BDQ, de forma a avaliar a pertinência de sua utilização no contexto sociocultural em nosso meio.

\section{MATERIAIS E MÉTODOS}

Este estudo foi realizado em uma escola pública da rede federal de ensino do Rio de Janeiro. A população da série abrangeu escolares de 15 a 18 anos de idade regularmente matriculados nas turmas de ensino médio dessa escola.

$\mathrm{O}$ instrumento utilizado foi o $\mathrm{BDQ}^{(38)}$, aplicado a 234 alunos do ensino médio da escola citada, no horário de aulas, sob supervisão da pesquisadora principal (M.T.A), em grupos de 20 a 30 adolescentes. Os alunos preenchiam separadamente o questionário e as possíveis dúvidas eram esclarecidas pela pesquisadora.

$\mathrm{O} \mathrm{BDQ}^{(38)}$ compreende opções de respostas dicotômicas e ordinais. $\mathrm{O}$ questionário começa com uma pergunta chave com resposta dicotômica ( $\mathrm{sim} /$ não) sobre se o indivíduo apresentou "alguma dor na barriga". Se a resposta for positiva, serão feitas 19 perguntas adicionais para caracterizar esta dor. Posteriormente, seguem 21 questões sobre outros sintomas e hábitos intestinais. No final há perguntas derivadas do "Psychosomatic Symptom Checklist", instrumento que fornece medida de somatização em que o entrevistado estima, através de uma escala de 0 a 4 pontos, com que freqüência 17 sintomas comuns ocorrem e o quanto eles o incomodam.

A avaliação da equivalência conceitual e de itens envolveu a discussão com um grupo de profissionais afeitos aos temas de saúde pública, gastroenterologia pediátrica e educação em saúde, formado por um médico epidemiologista, uma médica com especialização em História da Medicina, um médico com especialização em Educação em Saúde e uma especialista em Gastroenterologia Pediátrica. Nesta etapa discutiu-se a pertinência dos construtos abordados no questionário ${ }^{(38)}$ : a) dor abdominal e suas características, b) hábitos de evacuação, c) uso de medicamentos, d) procura por atendimento médico, e) uso de álcool e tabaco, f) interrupção das atividades diárias, g) história patológica pregressa e h) freqüência e grau de incômodo de determinados sintomas extra-intestinais.

A avaliação da equivalência semântica foi realizada em quatro etapas: a primeira consistiu na tradução do instrumento original em inglês para o português por um tradutor juramentado; na segunda etapa, a edição em português foi retrotraduzida por outro tradutor. A tradução e a retrotradução ocorreram de forma independente e mascaradas em relação aos profissionais envolvidos. Ambos conheciam os objetivos do trabalho. A terceira etapa consistiu na avaliação da equivalência, com ênfase no significado referencial e geral. A equivalência apreciada sob a ótica do significado referencial de termos e palavras diz respeito a correspondência literal entre eles. Já a equivalência do ponto de vista do significado geral de cada item transcende a interpretação literal e almeja captar uma correspondência do impacto emocional ou afetivo que estes termos provocam no respondente. $\mathrm{O}$ significado referencial foi apreciado entre o instrumento original e a edição retrotraduzida através de escalas analógicas visuais. Para a avaliação do significado geral confrontou-se as questões originais e as traduzidas, cuja equivalência foi avaliada em quatro níveis: inalterado, pouco alterado, muito alterado, e completamente alterado. Estas apreciações foram feitas de forma independente por dois médicos especialistas em Gastroenterologia Pediátrica e fluentes em inglês e português, cuja língua materna é o português. $\mathrm{Na}$ quarta etapa o grupo de especialistas que participou da avaliação da equivalência conceitual e de itens, discutiu os resultados 
obtidos nas etapas anteriores e propôs uma edição em língua portuguesa mais adequada, utilizando os itens traduzidos ou modificando-os.

Para a apreciação da equivalência de mensuração avaliou-se a confiabilidade, através da concordância e consistência interna dos itens do BDQ. A reprodutibilidade intra-observador foi apreciada repetindo-se a aplicação do questionário a 63 alunos, com intervalo de 10 a 17 dias entre a primeira e a segunda aplicação. O estado de saúde dos adolescentes que participaram do reteste foi apreciado pelas possíveis faltas à escola por motivos médicos no período que compreendeu o intervalo de tempo entre a primeira e a segunda aplicação do questionário. Vale ressaltar que neste período, de acordo com o relato da direção da escola, nenhum dos alunos faltou às aulas por motivos médicos.

Para as variáveis dicotômicas, a reprodutibilidade foi estimada pela estatística simples do kappa e os intervalos de confiança calculados utilizando-se um programa desenvolvido no aplicativo Stata $7.0^{(31)}$. Para a avaliação das variáveis ordinais, utilizou-se o índice de kappa ponderado com pesos quadráticos e o intervalo de confiança foi calculado via "bootstrap", com 1000 replicações ${ }^{(37,43)}$. O índice de kappa foi interpretado utilizando-se a classificação proposta por Landis e $\operatorname{Koch}^{(28,29)}$ em que são colocadas cinco categorias para as estimativas de confiabilidade, a partir dos valores encontrados para a estatística kappa: quase perfeita $(>0,80)$, substancial $(0,61$ a 0,80$)$, moderada $(0,41$ a 0,60$)$, regular $(0,21$ a 0,40$)$, fraca $(0,11$ a 0,20$)$ e pobre $(<0,1)$.

A confiabilidade foi também avaliada através da medida do montante de consistência interna, utilizando-se os dados da primeira aplicação do questionário e calculando-se o coeficiente alfa de Cronbach e respectivos intervalos de confiança de $95 \%$ para os itens que compõem grupos de doenças funcionais (dor abdominal crônica, constipação, síndrome do intestino irritável, dispepsia/refluxo) e os sintomas abordados no "Psychosomatic Symptom Checklist".

Os dados foram armazenados num programa criado para este fim no aplicativo EPI-INFO e analisados nos aplicativos STATA 6 e 7. Este estudo foi avaliado e aprovado pela Comissão de Ética em Pesquisa do Núcleo de Estudos em Saúde Coletiva da Universidade Federal do Rio de Janeiro.

\section{RESULTADOS}

\section{Características demográficas da população estudada}

Dentre os 321 alunos do ensino médio convidados a participar, 234 aceitaram, representando $73 \%$ da população abordada; 129 pertenciam ao sexo feminino e 105 ao sexo masculino $(55,13 \%$ vs. 44,87\%), com idades variando de 15 a 18 anos.

Equivalência conceitual e de itens

O painel de especialistas concluiu que os conceitos abarcados pelo instrumento original são relevantes no nosso meio.

\section{Equivalência semântica}

A Tabela 1 mostra os resultados da avaliação da equivalência semântica sob a perspectiva do significado geral de cada pergunta.
Na Tabela 2 estão os resultados da avaliação da equivalência semântica sob a perspectiva do significado referencial.

$\mathrm{Na}$ avaliação do significado referencial, oito questões e o item "stomach pain" na lista de sintomas apresentam percentual de concordância inferior a $70 \%$, mostrando que no processo de retrotradução houve perda do significado. Destaca-se a retrotradução do termo "barriga" para "stomach", que apesar de ter resultado em perda do significado referencial não afetou o significado geral, que se manteve inalterado ou pouco alterado.

TABELA 1 - Avaliação da equivalência semântica - comparação entre o significado geral de cada item do questionário original e da tradução para a língua portuguesa

\begin{tabular}{lcc}
\hline \multirow{2}{*}{ Significado geral } & \multicolumn{2}{c}{ Questões/ Instruções de preenchimento } \\
\cline { 2 - 3 } & $\mathbf{n}$ & $\%$ \\
\hline Inalterado & 85 & 92 \\
Pouco alterado & 7 & 8 \\
Muito ou completamente alterado & 0 & 0 \\
\hline
\end{tabular}

TABELA 2 - Avaliação da equivalência semântica - comparação entre o significado referencial de cada item do questionário original e da sua retradução para o inglês

\begin{tabular}{lcc} 
Percentual de concordância & Questões/Instruções para o preenchimento \\
\hline$>80 \%$ & n & $\%$ \\
$60 \%$ a $79 \%$ & 81 & 88,0 \\
$40 \%$ a $59 \%$ & 3 & 3,3 \\
$30 \%$ a $39 \%$ & 0 & 0 \\
$<30 \%$ & 4 & 4,35 \\
\hline
\end{tabular}

Equivalência de mensuração - confiabilidade

Para o reteste foram abordados 89 alunos, dos quais 63 concordaram em responder $(70,8 \%)$, o que representa $27 \%$ do total de alunos que responderam inicialmente. Esses alunos foram selecionados por ainda estarem freqüentando a escola, já que os demais haviam entrado de férias. Dentre os alunos que participaram do reteste, $55,6 \%$ pertenciam ao sexo feminino e $44,4 \%$ ao masculino, com idades de 15 a 18 anos, sendo que $90,5 \%$ dos alunos tinham entre 16 e 17 anos. As populações das duas aplicações não diferiam em relação ao gênero, porém houve predomínio de alunos com idades entre 16 e 17 anos na segunda aplicação.

A Tabela 3 resume os resultados da confiabilidade das questões do BDQ. Em quatro questões não foi possível determinar a confiabilidade pelos métodos estatísticos empregados, provavelmente porque o número de replicações foi muito pequeno. Por outro lado, em três questões não foi possível o cálculo do intervalo de confiança do kappa, possivelmente pelo mesmo motivo. Mais da metade das questões apresentaram concordância substancial a quase perfeita; a primeira pergunta do questionário apresentou estimativa de kappa 0,9 .

Neste estudo indivíduos foram classificados segundo as seguintes síndromes, de acordo com os critérios de Roma 
aplicados ao BDQ: dor abdominal não especificada, dispepsia, apenas dor epigástrica, síndrome do intestino irritável e ausência de dor. A Tabela 4 mostra as estimativas de ponto do kappa para as diversas doenças abordadas, indicando concordância para as síndromes apenas de regular a moderada.

\section{Equivalência de mensuração - consistência interna}

As doenças avaliadas foram aquelas mais comumente observadas na população: dor abdominal crônica não especificada, constipação, dispepsia/refluxo e síndrome do intestino irritável, além dos 17 sintomas abordados no check-list. Na Tabela 5 estão listados os valores dos coeficientes alfa de Cronbach e o limite inferior de seus respectivos intervalos de confiança de $95 \%$. Exceto para o check-list, que apresentou consistência muito boa, para as diferentes síndromes a consistência interna ficou em torno de 0,6 .

TABELA 3 - Confiabilidade do questionário traduzido de acordo com a classificação de Landis e Koch

\begin{tabular}{lcc}
\hline Classificação & Número de questões & $\%$ \\
\hline Ruim & 1 & 1,4 \\
Mínima & 1 & 1,4 \\
Razoável & 9 & 12,9 \\
Moderada & 16 & 22,9 \\
Substancial & 24 & 34,3 \\
Quase perfeita & 15 & 21,4 \\
Sem classificação & 4 & 5,7 \\
\hline
\end{tabular}

TABELA 4 - Confiabilidade intra-observador dos grupos de doenças funcionais, de acordo com a primeira aplicação do questionário e o reteste

\begin{tabular}{lcc}
\hline Grupo de doenças & kappa & IC95\% \\
\hline Dor epigástrica acima do umbigo mais de seis vezes & 0,57 & $0,25-0,88$ \\
Síndrome do intestino irritável & 0,31 & $0,10-0,73$ \\
$\begin{array}{l}\text { Dispepsia classificada como mais de 6 episódios de dor não } \\
\text { localizada apenas abaixo do umbigo }\end{array}$ & 0,50 & $0,20-0,80$ \\
Ausência de dor abdominal & 0,93 & $0,82-1,00$ \\
Mais de seis episódios de dor abdominal nos últimos 12 meses & 0,45 & $0,20-0,71$ \\
\hline
\end{tabular}

TABELA 5 - Coeficiente alfa de Cronbach para os principais grupos de sintomas

\begin{tabular}{llc}
\hline Grupos de sintomas & Total & IC 95\%* \\
\hline Dor abdominal recurrente & 0,74 & 0,69 \\
Constipação & 0,72 & 0,66 \\
Síndrome do intestino irritável & 0,67 & 0,59 \\
Dispepsia/refluxo & 0,66 & 0,61 \\
Check-list & 0,88 & 0,87 \\
\hline * Limite inferior, não é possível calcular o limite superior do coeficiente alfa de Cronbach &
\end{tabular}

\section{DISCUSSÃO}

As DGF são um problema de Saúde Pública e vêm ganhando crescente importância clínica, social e econômica. No entanto, o diagnóstico preciso é uma das principais dificuldades na abordagem de pacientes com suspeita de doenças funcionais. Métodos diagnósticos válidos, baseados num mínimo de exames complementares, teriam implicações óbvias para os pacientes e serviços de saúde em geral. Pesquisadores que estudam as DGF no mundo inteiro vêm, desde $1978^{(27)}$, buscando estabelecer critérios diagnósticos baseados em sintomatologia com o objetivo de discriminar entre pacientes com DGF e orgânicas. Esses especialistas se reúnem periodicamente e, atualmente, estão desenvolvendo os critérios de Roma III ${ }^{(11,12)}$, que serão uma revisão e atualização dos critérios diagnósticos previamente elaborados. Nesta perspectiva, o objetivo maior é estabelecer critérios universalmente aceitos, que possam ser aplicados em diferentes países, culturas, etnias, religiões, idiomas e faixas etárias.

Paralelamente, vários questionários para a aferição de sintomas gastrointestinais baseados nestes critérios vêm sendo elaborados. Observa-se, no entanto, que diversos autores, em várias instituições de pesquisa, cada qual com suas peculiaridades e inseridas em distintos contextos sociais e culturais, elaboram diferentes instrumentos com a finalidade de identificar pacientes com DGF. É notável o esforço para o estabelecimento de critérios diagnósticos para as mesmas, mas a aferição baseada em instrumentos nem sempre validados pode comprometer a qualidade das informações obtidas e, por conseqüência, gerar diagnósticos incorretos.

No final da década de 80 observou-se também crescente preocupação no que concerne à validade de instrumentos de aferição da qualidade de vida relacionada à saúde, assim como a sua ampla utilização em diversos contextos socioculturais. A aferição dos vários aspectos relacionados à qualidade de vida, assim como dos sintomas gastrointestinais que compõem as DGF, não se baseia em marcadores físicos, químicos ou biológicos com os quais possam ser comparados. Assim como na avaliação da qualidade de vida, a percepção, a valorização e a caracterização dos sintomas gastrointestinais podem sofrer grandes variações étnicas, culturais e sociais. Nessas circunstâncias, torna-se necessário realizar algum tipo de adaptação cultural dos instrumentos de aferição, de forma a viabilizar a sua aplicação a uma população num contexto sociocultural diferente daquele em que foi elaborado.

Considerando as relativas similaridades da problemática da aferição das dimensões da qualidade de vida e das DGF, este trabalho utilizou metodologias extensivamente investigadas e utilizadas para a tradução e adaptação transcultural de instrumentos que avaliam a qualidade de vida relacionada à saúde, para adaptar o BDQ ao nosso contexto sociocultural

Não há na literatura consenso sobre a tradução e adaptação cultural de instrumentos para a aferição de sintomas gastrointestinais. Nas situações em que o BDQ foi aplicado em outras culturas, que não aquela em que foi elaborado, não há relato de apreciação da sua adaptação transcultural ${ }^{(20,21,33)}$. Quando o BDQ foi aplicado nos EUA numa população de adolescentes, não foi realizada uma adaptação formal, mas sim um teste em campo em que o instrumento pareceu ser facilmente compreendido por essa população ${ }^{(23)}$. Para aplicação na Singapura, o BDQ foi traduzido para o chinês e malaio e testada sua aceitabilidade e replicabilidade nesse novo contexto, porém não foi realizada adaptação transcultural formal ${ }^{(20)}$. 
Neste estudo seguiu-se o modelo universalista proposto por HERDMAN et al. ${ }^{(19)}$ para a tradução e adaptação de instrumentos, com o objetivo de avaliar a qualidade de vida relacionada à saúde.

No presente processo de tradução e adaptação cultural deste instrumento, o grupo de discussão formado para avaliar as equivalências conceitual e de itens, entendeu que os conceitos abordados pelo BDQ foram interpretados de forma semelhante no presente contexto sociocultural e os itens abarcavam adequadamente os domínios estudados. Os itens abordados no questionário são pertinentes na nossa cultura, tanto os que se referem a sintomas gastrointestinais, quanto aqueles relacionados a hábitos como consumo de álcool, tabagismo, dados sociodemográficos, procura por atendimento médico, história patológica pregressa, uso de medicamentos e sintomas gerais. O grupo concordou que todos os itens captam adequadamente os domínios avaliados no questionário original

Admite-se que os conceitos de dor abdominal ou outros sintomas gastrointestinais, hábitos intestinais, procura por atendimento médico, uso de medicamentos, história de doenças prévias e interferência desses sintomas nas atividades sejam universais. Uma limitação desta etapa da avaliação reside no fato de que os conceitos abarcados pelo BDQ não foram previamente discutidos com a população de adolescentes. Autores ${ }^{(30,32)}$ alertam para o fato de que, no processo de adaptação de um questionário a uma nova cultura, é importante realizar grupos focais com a população a que se dirige para conhecer os significados que são dados aos conceitos abordados no questionário.

A tradução do questionário resultou na primeira edição em língua portuguesa do BDQ, que foi revista pelo grupo de discussão, obtendo-se a edição que foi aplicada aos adolescentes. Poucas palavras ou expressões foram modificadas. $\mathrm{O}$ item que aborda a profissão e tipo de trabalho gerou muitas dúvidas, uma vez que a maioria dos entrevistados não sabia como distinguir estes dois aspectos. Muitos também não conseguiam recordar o início da dor. Provavelmente as perguntas que geraram dúvidas poderiam ser substituídas ou melhor esclarecidas se a avaliação da equivalência conceitual e de itens tivesse considerado a participação de adolescentes. Apesar desses problemas pontuais, não houve dificuldade no que tange a aceitabilidade do questionário, os adolescentes se sentiram à vontade para respondê-lo e relataram experiências próprias de sintomas gastrointestinais abordados por ele.

Autores $^{(30,35)}$ enfatizam a importância de se utilizar e se confrontar mais de uma tradução, o que permite a escolha e a composição de itens oriundos de diferentes versões. No presente trabalho, por problemas operacionais, não foi possível obter outra tradução do questionário. No caso específico da adaptação do BDQ, apesar do reconhecimento dos potenciais ganhos que poderiam ter sido obtidos pela inclusão de adolescentes nos grupos de discussão e pelo uso de mais de um par de traduçãoretradução, julga-se que uma única tradução foi suficiente para a elaboração da edição em português do BDQ semanticamente equivalente ao instrumento original.

No que tange a avaliação da equivalência operacional, a forma como o questionário foi aplicado (anônimo e voluntário), não diferiu do original. Nos EUA e na Sibéria, a aplicação aos adolescentes foi feita durante o período de aulas em escolas aleatoriamente selecionadas ${ }^{(23,33)}$. Quando da elaboração do $\mathrm{BDQ}$, os respondentes eram pacientes que procuraram atendimento na clínica gastroenterológica, clínica da dor ou na divisão de medicina preventiva ${ }^{(39)}$. Em trabalhos subseqüentes, o questionário foi enviado pelo correio a uma população aleatoriamente selecionada ${ }^{(3,40,41,42,45)}$. Não há estudos comparando o modo de aplicação do BDQ, entretanto parece razoável comparar os resultados obtidos no presente estudo com aqueles de RESHETNIKOV et al. ${ }^{(33)}$ e HYAMS et al. ${ }^{(23)}$, uma vez que todos foram respondidos em ambiente escolar e durante o horário de aulas.

De acordo com a classificação de Landis e Koch, 11 questões do BDQ apresentaram confiabilidade ruim, mínima ou razoável. Embora a primeira pergunta do questionário apresente uma classificação quase perfeita, vale ressaltar que as duas respostas discordantes ocorreram no sentido da afirmação na primeira e negação na segunda aplicação, o que pode indicar interesse pelo participante de preencher mais rapidamente o questionário, já que as 19 questões subseqüentes são respondidas apenas por aqueles que apresentaram dor nos últimos 12 meses.

O item que aborda a localização da dor abdominal apresentou baixa concordância, provavelmente porque na prática clínica, muitas vezes esta característica é de difícil definição. Outros itens com baixa confiabilidade referem-se à relação da dor com as refeições, informação também de difícil caracterização, uma vez que a percepção da dor limitada ao tempo é imprecisa. Duas questões referindo-se ao número de evacuações por semana também apresentaram concordância insatisfatória. As discordâncias ocorreram em ambos os sentidos, porém ninguém afirmou menos de três evacuações por semana na primeira aplicação e mais de três por dia na segunda ou vice-versa. Dados da literatura mostram que de $94 \%$ a $97 \%$ das pessoas apresentam freqüência de evacuação entre três por dia e três por semana ${ }^{(7,9)}$. No presente estudo, $80 \%$ dos adolescentes apresentavam esse padrão de evacuação.

Outro item com baixa confiabilidade no presente estudo é um dos três respondidos apenas por aqueles que já encontraram algum sangue no vaso sanitário ou nas fezes no último ano, representado por $13 \%$ dos entrevistados. O pequeno número de pessoas avaliadas pode explicar os resultados insatisfatórios da confiabilidade dessa questão.

A baixa concordância também observada no item que se refere a algum episódio de dor abdominal na infância pode dever-se ao fato do assunto por ele abordado referir-se a um episódio ocorrido há muito tempo, podendo introduzir neste caso um viés de memória. Outra possível explicação seria o fato da primeira aplicação do questionário ter sensibilizado os informantes no sentido de recordar com maior interesse os episódios dolorosos ocorridos na infância.

Neste estudo foram calculados os valores de kappa também para os seguintes grupos: indivíduos com dor abdominal crônica não especificada, com dispepsia, apenas dor epigástrica, indivíduos com síndrome do intestino irritável e normais. Observou-se que a confiabilidade do diagnóstico de síndrome do intestino irritável foi muito baixa $(\mathrm{k}=0,31)$. Há duas possíveis explicações para este resultado: o instrumento não se presta ao diagnóstico desse 
distúrbio na população estudada, ou o número de replicações foi muito pequeno, fazendo com que o número de indivíduos com esta condição no reteste fosse também baixo.

Na classificação de dispepsia, que envolve três itens do questionário: presença de dor, mais de seis episódios nos últimos 12 meses e sua localização, número considerável de adolescentes classificados sem dispepsia na primeira aplicação apresentava esta condição no reteste. A concordância do item que abordava a localização da dor foi muito baixa, o valor do kappa na abordagem de pessoas que apresentavam dor não localizada apenas abaixo da cicatriz umbilical foi de $0,46,0$ que provavelmente contribuiu para a baixa confiabilidade observada também na abordagem desse distúrbio.

Os indivíduos classificados como apresentando apenas dor epigástrica preenchiam dois critérios: dor abdominal mais que seis vezes e localização acima da cicatriz umbilical. Nesse distúrbio, a confiabilidade pode ser baixa em função do erro de classificação da localização da dor, aspecto já comentado anteriormente.

Por último, as pessoas saudáveis são aquelas que não apresentaram dor abdominal nos últimos 12 meses e a estimativa de ponto do kappa foi 0,90 .

De maneira geral, observou-se que a concordância foi satisfatória para a maioria dos itens do questionário, mas baixa para a avaliação sindrômica. É possível que a baixa prevalência de certas doenças necessárias para o diagnóstico destas síndromes, aliado ao pequeno tamanho amostral deste estudo de confiabilidade, tenham contribuído para isto. Admite-se que, em geral, há boa confiabilidade das informações individuais fornecidas pelo questionário adaptado, mas é possível que os critérios para o diagnóstico sindrômico necessitem ser revistos e/ou flexibilizados para sua utilização no nosso contexto sociocultural.

Não há, na literatura, estudos que abordem a consistência interna utilizando o BDQ. No entanto, em geral, os resultados encontrados demonstram boa consistência interna das questões relacionadas às principais doenças funcionais e particularmente daquelas referentes aos sintomas extra-intestinais, abordados no check-list.
Os resultados apresentados nas diversas etapas da adaptação transcultural foram satisfatórios, portanto a edição em língua portuguesa do BDQ mostrou ser funcionalmente equivalente à edição original.

Este estudo veio mostrar a importância de se adaptar culturalmente instrumentos para a aferição de DGF, cujo diagnóstico é eminentemente baseado em sintomas. Assim como as dimensões subjetivamente avaliadas no que tange à qualidade de vida, a percepção, valorização e caracterização dos sintomas gastrointestinais podem sofrer grandes variações culturais e sociais.

\section{CONCLUSÕES}

Verificou-se que, utilizando a metodologia proposta por HERDMAN et al. ${ }^{(19)}$, foi possível obter uma edição do BDQ adequadamente adaptada ao nosso contexto sociocultural.

Esta constitui a primeira fase para a obtenção de instrumento de medida de DGF na população de adolescentes, porém pretende-se aprimorar esta edição para sua subseqüente utilização em amplas populações de adolescentes. Este trabalho também pretende alertar para a necessidade do uso de instrumentos validados e culturalmente adaptados para garantir a qualidade das informações epidemiológicas em estudos que avaliam DGF. Aos instrumentos de aferição de DGF deve ser dado o mesmo valor que aos critérios diagnósticos, sob pena de se comprometer em muito a qualidade das informações obtidas e por conseqüência o diagnóstico, o tratamento, o prognóstico e a qualidade de vida dos indivíduos acometidos.

\section{AGRADECIMENTOS}

Agradecemos à diretora do Colégio de Aplicação da Universidade Federal do Rio de Janeiro, Profa. Miltza Bakich Putziger, e a todos os professores dessa instituição, cuja colaboração foi fundamental para este trabalho.

Aires MT, Werneck GL. Portuguese-language cultural adaptation and translation of "The bowel disease questionnaire" used to assess functional bowel disorders. Arq Gastroenterol 2006;43(2):138-53.

ABSTRACT - Background - Functional bowel disorders are considered a public health problem, but there are a few prevalence studies in Brazil. In 1999, researchers from the Mayo Clinic developed The Bowel Disease Questionnaire with the purpose to evaluate functional bowel disorders. Although this has been used in different studies and population, it is often necessary to perform a cultural adaptation of a questionnaire developed for use in another culture, in order to improve the quality of the information obtained. Objective - To translate and adapt the Bowel Disease Questionnaire to Portuguese for its use in adolescents. Methods - Assessment of conceptual and item equivalence involved evaluation of the pertinence of the concepts in the Brazilian context; translation was evaluated through semantic equivalence between the original instrument and the Portuguese version; measurement equivalence between the original and the Portuguese version was assessed by the intra-observer reliability and internal consistency. Results - The Bowel Disease Questionnaire's concepts were considered pertinent in the Brazilian context; the semantic equivalence between the original and the Portuguese version were high; reliability ranged from moderate to almost perfect; internal consistency of the scales ranged from 0,66 to 0,74 . Conclusion - The Portuguese version of the Bowel Disease Questionnaire seems to be semantically and culturally equivalent to the original version and might be useful for measuring functional bowel disorders among Brazilian adolescents.

HEADINGS - Intestinal diseases. Colonic disease, functional. Dyspepsia. Teen health. Questionnaires. Validity. 


\section{REFERÊNCIAS BIBLIOGRÁFICAS}

1. Agréus L, Svardsudd K, Nyrén O, Tibblin, G. The epidemiology of abdominal symptoms: prevalence and demographic characteristics in a Swedish adult population. Scand J Gastroenterol. 1994;29:102-9.

2. Agréus L, Svardsudd K, Nyrén O, Tibblin G. Irritable bowel syndrome and dyspepsia in the general population: overlap and lack of stability over time. Gastroenterology. 1995; 109:671-80

3. Agréus L, Talley NJ, Svardsudd K, Tibblin G, Jones MP. Identifying dyspepsia and irritable bowel syndrome: the value of pain or discomfort, and bowel habit descriptors. Scand J Gastroenterol. 2000;35:142-51.

4. Agréus L, Svardsudd K, Talley NJ, Jones MP, Tibblin G. Natural history of gastroesophageal reflux disease and functional abdominal disorders: a population-based study. Am J Gastroenterol. 2001;96:2905-14

5. Bullinger M, Alonso J, Apolone G, Leplege A, Sullivan M, Wood-Dauphinee S, Gandek B, Wagner A, Aaronson N, Bech P, Fukuhara S, Kaasa S, Ware JE Jr. Translating health status questionnaire and evaluating their quality: the IQOLA projecy approach. J Clin Epidemiol. 1998;51:913-23.

6. Camillieri M. Management of the irritable bowel syndrome. Gastroenterology. 2001;120:652-68

7. Chen LY, Ho KY, Phua KH. Normal bowel habits and prevalence of functional bowel disorders in Singaporean adults - findings from a community based study in Bishan Singapore Med J. 2000;41:255-8.

8. Corazziari E. Definition and epidemiology of functional gastrointestinal disorders. Best Pract Res Clin Gastroenterol. 2004;18:613-31.

9. Drossman DA, Sandler RS, Mckee DC, Lovitz AJ. Bowel patterns among subjects not seeking health care. Use of a questionnaire to identify a population with bowel dysfunction. Gastroenterology. 1982;83:529-34.

10. Drossman DA, Li Z, Toner BB, Diamant NE, Creed FH, Thompson D, Read NW, Babbs C, Barreiro M, Bank L, et al. Functional bowel disorders: a multicenter comparison of health status and development of illness severity index. Dig Dis Sci. 1995;40:986-95.

11. Drossman DA. The functional gastrointestinal disorders and the Rome II process. Gut. 1999:45(Suppl II):II1-II5.

12. Drossman DA, editor. Rome II: the functional gastrointestinal disorders diagnosis, pathophysiology and treatment: a multinational consensus. $2^{\text {nd }}$ ed. McLean, VA: Dengon Associates; 2000.

13. El-Serag HB, Talley NJ. Systematic review: health-related quality of life in functional dyspepsia. Aliment Pharmacol Ther. 2003;18:387-93.

14. Eslick GD, Howell SC, Hammer J, Talley NJ. Empirically derived symptom sub-groups correspond poorly with diagnostic criteria for functional dyspepsia and irritable bowel syndrome. A factor and cluster analysis of a patient sample. Aliment Pharmacol Ther. 2004;19:133-40.

15. Friedman LS. Rome II: the functional gastrointestinal disorders. N Engl J Med. 2001;345:71-2

16. Gralnek IM, Hays RD, Kilbourne A, Naliboff B, Mayer EA. The impact of irritable bowel syndrome on health-related quality of life. Gastroenterology. 2000;119:654-60.

17. Guillemin F, Bombardier C, Beaton D. Cross-cultural adaptation of health-related quality of life measures: literature review and proposed guidelines. J Clin Epidemiol. 1993;46:1417-32

18. Halder SL, Locke GR 3rd, Talley NJ, Fett SL, Zinsmeister AR, Melton LJ 3rd. Impact of functional gastrointestinal disorders on health-related quality of life: a populationbased case-control study. Aliment Pharmacol Ther. 2004;19:233-42.

19. Herdman M, Fox-Rushby J, Badia X. A model of equivalence in the cultural adaptation of HRQoL instruments: the universalist approach. Qual Life Res. 1998;7:323-35.

20. Ho KY, Kang JY, Seow A. Prevalence of gastrointestinal symptoms in a multiracial Asian population, with particular reference to reflux-type symptoms. Am J Gastroenterol. 1998:93:1816-22.

21. Holtmann G, Goebell H, Talley NJ. Functional dyspepsia and irritable bowel syndrome: is there a common pathophysiological basis? Am J Gastroenterol. 1997;92:954-9.

22. Hyams JS, Treem WR, Justinich CJ, Davis P, Shoup M, Burke G. Characterization of symptoms in children with recurrent abdominal pain: resemblance to irritable bowel syndrome. J Pediatr Gastroenterol Nutr. 1995;20:209-14.

23. Hyams JS, Burke G, Davis PM, Rzepski B, Andrulonis PA. Abdominal pain and irritable bowel syndrome in adolescents: a community-based study. J Pediatr. 1996;129:220-6.

24. Hyams JS, Davis P, Sylvester FA, Zeiter DK, Justinich CJ, Lerer T. Dyspepsia in children and adolescents: a prospective study. J Pediatr Gastroenterol Nutr. 2000;30:413-8.
25. Locke GR 3rd, Talley NJ, Fett SL, Zinsmeister AR, Melton LJ 3rd. Prevalence and clinical spectrum of gastroesophageal reflux: a population based study in Olmsted county, Minnesota. Gastroenterology. 1997;112:1448-56.

26. Locke GR 3rd, Yawn BP, Wollan PC, Melton LJ 3rd, Lydick E, Talley NJ. Incidence of a clinical diagnosis of the irritable bowel syndrome in a United States population. Aliment Pharmacol Ther. 2004;19:1025-31.

27. Manning AP, Thompson WG, Heaton KW, Morris AF. Towards a positive diagnosis of irritable bowel. Br Med J. 1978;2:653-4.

28. Morgenstern H. Epidemiologic methods I - Class notes. Los Angeles: Division of Epidemiology, UCLA School of Public Health; 1995.

29. Moser CA, Kalton G. Scaling methods. In: Moser CA, Kalton G. Survey methods in social investigation. $2^{\text {nd }}$ ed London: Heinemann Educational; 1971.

30. Reichenheim ME, Hasselman MH, Moraes CL. Equivalência semântica da versão em português do instrumento Abuse Assessment Screen para rastrear a violência contra a mulher grávida. Rev Saúde Pública. 2000;34:610-6.

31. Reichenheim ME. Confidence interval for the kappa-statistic of interrater agreement (kapci2.ado for Stata 7.0). Rio de Janeiro: Instituto de Medicina Social/UERJ; 2001.

32. Reichenheim ME, Moraes CL. Buscando a qualidade das informações em pesquisas epidemiológicas. In: Minayo, MCS. Caminhos do Pensamento: Epistemologia e Método. Rio de Janeiro: Fiocruz; 2002.

33. Reshetnikov OV, Kurilovich SA, Denisova DV, Zavyalova LG, Tereshonok IN. Prevalence of dyspepsia and irritable bowel syndrome among adolescents of Novosibirsk, western Siberia. Int J Circumpolar Health. 2001;60:253-7.

34. Sandler RS, Stewart WF, Liberman JN. Abdominal pain, bloating and diarrhea in the United States: prevalence and impact. Dig Dis Sci. 2000;45:1166-71.

35. Serra-Sutton V, Herdman M, Rajmil L, Santed R, Ferrer M, Simeoni MC, Auquier P. Adaptación al Español del cuestinariio Vecú et Sante Perçue de l'Adolescent (VSP-A): una medida genérica de calidad de vida para adolescentes. Rev Esp Salud Publica. 2002;76:701-12.

36. Spiller R. Rome II: the functional gastrointestinal disorders. Diagnosis, Pathophysiology and Treatment: a Multinational Consensus. Gut 2000;46:741.

37. StataCorp. Stata Statistical Software: Release 7.0. College Station, Tx: Stata Corporation; 2001

38. Talley NJ, Phillips SF, Melton J 3rd, Wiltgen C, Zinsmeister AR. A patient questionnaire to identify bowel disease. Ann Intern Med. 1989;111:671-4.

39. Talley NJ, Phillips SF, Wiltgen CM, Zinsmeister AR, Melton LJ 3rd. Assessment of functional gastrointestinal disease: the bowel disease questionnaire. Mayo Clin Proc. 1990;65:1456-79.

40. Talley NJ, Zinsmeister AR, Van Dyke C, Melton LJ 3rd. Epidemiology of colonic symptoms and the irritable bowel syndrome. Gastroenterology. 1991;101:927-34

41. Talley NJ, Weaver AL, Zinsmeister AR, Melton LJ 3rd. Onset and disappearance of gastrointestinal symptoms and functional gastrointestinal disorders. Am J Epidemiol. 1992;136:165-77.

42. Talley NJ, Zinsmeister AR, Schleck CD, Melton LJ 3rd. Dyspepsia and dyspepsia subgroups: a population-based study. Gastroenterology. 1992;102:1259-68.

43. Talley NJ, Gabriel SE, Harmsen WS, Zinsmeister AR, Evans RW. Medical costs in community subjects with irritable bowel syndrome. Gastroenterology. $1995 ; 109: 1736-41$

44. Talley NJ, Weaver AL, Zinsmeister AR. Impact of functional dyspepsia on quality of life. Dig Dis Sci. 1995;40:584-9.

45. Talley NJ, Zinsmeister AR, Melton LJ. Irritable bowel syndrome in a community: symptom subgroups, risk factors, and health care utilization. Am J Epidemiol. $1995 ; 142: 76-83$

46. Talley NJ, Holtmann G, Agréus L, Jones M. Gastrointestinal symptoms and subjects cluster into distinct upper and lower groupings in the community: a four nations study. Am J Gastroenterol. 2000;95:1439-47.

47. Whitehead WE, Burnett CK, Cook EW, Taub E. Impact of irritable bowel syndrome on quality of life. Dig Dis Sci. 1996;41:2248-53. 


\title{
Anexo - Questionário original
}

\author{
Bowel Disease Questionnaire
}

First, we would like to ask you some questions about any stomach, belly or tummy pain in the last year.

1. Have you had an ache or pain in your stomach or belly (gut) in the last year? (check answer)

1. $\square$ Yes

2. $\square$ No

(Please do NOT count cramps or pain with menstrual periods, and do NOT count pain in your chest)

\begin{tabular}{c|c}
\hline $\begin{array}{c}\text { If yes, please answer the } \\
\text { following questions }\end{array}$ & $\begin{array}{c}\text { If you have had no pain, } \\
\text { please go to question } 22 \text { on } \\
\text { page146 }\end{array}$ \\
\hline
\end{tabular}

Stomach or belly pain can be difficult to describe and sometimes more than one type of pain can occur. Please think about the usual or primary type of pain you have. We would like to ask you some questions only about the usual or primary pain in your stomach or belly.

2. Have you had this same ache or pain more than six times in the past year? (check answer)

$1 . \square$ Yes

2. $\square$ No

3. How bad is the ache or pain usually? (check answer)

1. $\square$ Mild: can be ignored it if you don't think about it

2. Moderate: cannot be ignored, but does not affect your life-style

3. Severe: affects your life-style

4. $\square$ Very severe: markedly affects your life-style

4. Pain can occur mainly in the upper belly (stomach), lower belly, or in both the upper and lower belly. Concerning your primary pain: Has this ache or pain in your belly usually been: (check answer)

1. $\square$ Above the navel, that is, in upper belly?

2. $\square$ Below the navel, that is, in the lower belly?

3. In different places in both the upper and lower belly?

5. Does your ache or pain ever wake you from sleep at night? (mark the answer) 1. $\square$ Yes

2. $\square$ No

6. Does this pain come and go periodically? Periodically here means periods of at least a month with no pain with periods in between weeks to months when there is pain. (check answer)

1. $\square$ Yes

2. $\square$ No
7. How many times did you get this pain in the last year? (check answer)
1. $\square$ Less than once a month
2. $\square$ About once a month
3. $\square$ About once a week
4. $\square$ Several times a week
5. Daily

8. When this pain occurs, how long does it usually last? (check answer)

1. $\square$ Less than 30 minutes

2. $\square 30$ minutes to 2 hours

3. More than 2 hours to 6 hours

4. $\square$ More than 6 hours

9. When in your life did this ache or pain first begin as close as you can recall? (check answer)

1. In the last 6 months

2. $\square 7$ months to 1 year ago

3. More than 1 year to 2 years ago

4. $\square$ More than 2 years to 5 years ago

5. $\square$ More than 5 years to 10 years ago

6. $\square$ More than 10 years to 20 years ago

7. $\square$ More than 20 years ago

10. Does this ache or pain often occur before meals or when hungry? (check answer)

$$
\begin{aligned}
& 1 . \square \text { Yes } \\
& 2 . \square \text { No }
\end{aligned}
$$

Please note: when we say often, we mean more than $25 \%$ of the time

11. Does this ache or pain often occur immediatelly after (less than 30 minutes) meals? (check answer)

$$
\text { 1. } \square \text { Yes }
$$$$
\text { 2. } \square \text { No }
$$

12. Does this ache or pain often occur 30 minutes to 2 hours after meals? (check answer)

$$
\text { 1. } \square \text { Yes }
$$$$
\text { 2. } \square \text { No }
$$

13. Is this pain often made better (relieved) by burping (bringing up air through the mouth)? (check answer)

$$
\begin{aligned}
& \text { 1. } \square \text { Yes } \\
& 2 . \square \text { No }
\end{aligned}
$$

14. Is this pain often made better by having a bowel movement? (check answer)

$$
\text { 1. } \square \text { Yes }
$$

$$
\text { 2. } \square \text { No }
$$

15. Is this pain often made better by eating?

$$
\begin{aligned}
& \text { 1. } \square \text { Yes } \\
& \text { 2. } \square \text { No }
\end{aligned}
$$


16. Is this pain often made better by taking antacids (like Tums, Riopan, Mylanta, Maalox, Gaviscon or Rolaids)? (check answer)

1. $\square$ Yes

2. $\square$ No

3. I don't take antacids

17. Is this pain often made worse by food or milk? (check answer)

1. $\square$ Yes

2. $\square$ No

18. Is this pain often made worse by drinking alcohol like beer, wine or other liquors? (check answer)
1. $\square$ Yes
2. No
3. $\square$ I don't drink alcohol

19. Does this pain often travel anywhere outside the belly? (check answer)

1. $\square$ Yes

2. No

20. Do you often have more bowel movements when this pain begins? (check answer)

1. $\square$ Yes
2. $\square$ No

21. Do you often have looser bowel movements (stools) when this pain begins? (check answer)

1. $\square$ Yes

2. No

An important purpose of this study is learn about bowel habits in the community in the last year.

22. Has your bowel habit changed in the last year? (check answer)

$$
\text { 1. } \square \text { Yes }
$$$$
\text { 2. } \square \text { No }
$$

23. How would you describe your usual bowel pattern in the last year? (check answer)
1. $\square$ Normal
2. $\square$ Constipated
3. $\square$ Diarrhea
4. $\square$ Alternating constipation and diarrhea

24. How many bowel movements do you usually have in a week? (check answer)

$1 . \square 1$ or less

$2 . \square 2$

3. $3-4$

4. 5-8

5. $\square-12$

6. 13-16

7. $17-21$

8. 22-26

9. $\square$ More than 26

25. Do you take anything (e.g. bran, fiber, laxatives) because of constipation? (check answer)

1. $\square$ Yes

2. $\square$ No

What?

How often?
26. Have you seen mucus in your stools in the last year (that is, white or green slimy material)? (check answer)

$$
\begin{aligned}
& \text { 1. } \square \text { Yes } \\
& 2 . \square \text { No }
\end{aligned}
$$

27. Do you often have less than 3 bowel movements each week? (check answer)

$$
\text { 1. } \square \text { Yes }
$$$$
\text { 2. } \square \text { No }
$$

Please note: when we say often, we mean more than $25 \%$ of the time.

28. Do you often have more than 3 bowel movements each day? (check answer)

$$
\text { 1. } \square \text { Yes }
$$

$$
\text { 2. } \square \text { No }
$$

29. Do you often strain to have a bowel movement? (check answer)

$$
\begin{aligned}
& \text { 1. } \square \text { Yes } \\
& \text { 2. } \square \text { No }
\end{aligned}
$$

30. Are your stools often loose or watery? (check answer)

$$
\text { 1. } \square \text { Yes }
$$

$$
\text { 2. } \square \text { No }
$$

31. Are your stools often hard? (check answer)

1. $\square$ Yes

2. $\square$ No

32. After finishing a bowel movement, do you often feel there is still stool that needs to be passed?

(check answer)

$$
\text { 1. } \square \text { Yes }
$$

2. $\square$ No

33. Do you often experience an urgent need to open your bowels that makes you rush to a toilet? (check answer)

$$
\text { 1. } \square \text { Yes }
$$

$$
\text { 2. } \square \text { No }
$$

34. Have you noticed any blood in your stools or in the toilet bowl in the last year? (check answer)

$$
\text { 1. } \square \text { Yes }
$$

2. $\square$ No

\begin{tabular}{r|c}
\hline If yes to question Q-34: & If no blood, go to Q-38 on \\
please answer Q-35 to Q-37 & next page \\
\hline
\end{tabular}

35. Is the blood coating the stools? (check answer)

$$
\begin{aligned}
& \text { 1. } \square \text { Yes } \\
& 2 . \square \text { No }
\end{aligned}
$$

36. Is the blood dark and mixed in the stools? (check answer)

$$
\text { 1. } \square \text { Yes }
$$$$
\text { 2. } \square \text { No }
$$

37. Is the blood on the toilet paper? (check answer)

$$
\begin{aligned}
& 1 . \square \text { Yes } \\
& 2 . \square \text { No }
\end{aligned}
$$

Please check that all questions that pertain to you have been answered 
Next, we would like to ask you about other complaints.

38. How many times have you had a feeling of wanting to throw up (nausea) in the last year? (check answer)

$0 . \square$ None

1. $\square$ Less than once a month

2. $\square$ About once a month

3. $\square$ About once a week

4. $\square$ Several times a week

5. $\square$ Daily

39. How many times have you actually thrown up (vomited) in the last year? (check answer)

$0 . \square$ None

1. $\square$ Less than once a month

2. $\square$ About once a month

3. $\square$ About once a week

4. $\square$ Several times a week

5. $\square$ Daily

40. Do you often feel bloated and actually see your belly swell up? (check answer)

$$
\text { 1. } \square \text { Yes }
$$

2. $\square$ No

41. Have you often had difficulty swallowing ( food sticking in your throat) in the last year? (check answer)

1. $\square$ Yes

2. $\square$ No

42. Have you had heartburn (a burning or ache behind the breast bone in the chest) in the last year? (check one answer)

0. $\square$ None

1. $\square$ Less than once a month

2. $\square$ About once a month

3. $\square$ About once a week

4. $\square$ Several times a week

5. $\square$ Daily

If you had heartburn: $\quad$ If no heartburn, go to Question 44

43. Is your heartburn made better by taking antacids (like Tums, Riopan, Mylanta, Maalox, Gaviscon or Rolaids)? (check one answer)

1. $\square$ Yes

2. $\square$ No

3. $\square$ I don't take antacids

44. Have you noticed a very sour or acid tasting fluid at the back of your throat in the last year? (check one answer)

$0 . \square$ None

1. $\square$ Less than once a month

2. $\square$ About once a month

3. $\square$ About once a week

4. $\square$ Several times a week

5. $\square$ Daily

45. Have you lost weight in the last year without deliberately dieting? (check one answer)

$0 . \square$ No

1. $\square$ Less than $7 \mathrm{lbs}$

2. $\square$ Lbs or more

46. Is your appetite in the last year compared with before: (check one answer) $0 . \square$ Decreased?

1. $\square$ About the same?

2. $\square$ Increased?
Another important purpose of this study is to learn about your previous health and visits to the doctor.

47. Did you have many bouts of stomach or belly pain as a child (before age 15)? (check answer)

1. $\square$ Yes

2. $\square$ No

48. Have you had your appendix out? (check answer)

1. $\square$ Yes

2. $\square$ No

49. Have you had your gallbladder taken out? (check answer)

1. $\square$ Yes

2. $\square$ No

If yes, when?

50. Have you ever had a stomach (gastric) or duodenal ulcer? (check answer)

1. $\square$ Yes

2. $\square$ No

If yes, when?

How was it diagnosed (by X-rays, endoscopy)?

51. Have you ever had an operation in your stomach? (check answer)

1. $\square$ Yes

2. $\square$ No

If yes, when?

What operation?

52. Have you ever had any other type of bowel/belly surgery? (check answer)

1. $\square$ Yes

2. $\square$ No

If yes, when?

What operation?

53. How many times have you visited a doctor or physician in the last year? (check one answer)

$0 . \square$ Never

1. $\square$ 1-2 Times

2. $\square$ 3-5 Times

3. $\square$ 6-10 Times

4. $\square$ More than 10 times

54. If you visited a doctor in the last year, was it for aches or pains in your belly? (check answer)

1. $\square$ Yes

2. $\square$ No

\begin{tabular}{c|c}
\hline $\begin{array}{c}\text { If yes to Q-54: please answer } \\
\text { Q-55 to Q-57 }\end{array}$ & If no, go to question Q-58 \\
\hline
\end{tabular}

55. If you did visit the doctor for belly pain, was it because the symptoms were severe or very severe? (check answer)

1. $\square$ Yes

2. $\square$ No

56. If you did visit the doctor for belly pain, was it because the symptoms worried you a lot? (check answer)

1. $\square$ Yes

2. $\square$ No

57. If you did visit the doctor for belly pain, was it because you believed you might have a serious disease? (check answer)

1. $\square$ Yes

2. $\square$ No 
58. If you visited a doctor in the last year, was it for problems with your bowels? (check answer)

\section{1. $\square$ Yes}

2. $\square$ No

59. How many colds or flu have you had in the last year? (check answer)
$0 . \square$ None
$1 . \square 1-2$
2. $\square$ 3-5
3. $\square-10$
4. $\square$ More than 10

Please check that all questions that pertain to your case have been answered

To help interpret the results of this survey, we would like to ask some questions about your activities, habits, work, and educational background. Please be assured that all information will be kept strictly confidential.

60. Have your activities been interrupted in the last year because of aches or pains in your stomach or tummy? (check answer)

$$
\text { 1. } \square \text { Yes }
$$

2. $\square$ No

61. Have your activities been interrupted in the last year because of problems with your bowels? (check answer)

$$
\text { 1. } \square \text { Yes }
$$

2. $\square$ No

62. Have your activities been interrupted in the last year because of other illnesses?(check answer)
1. $\square$ Yes
2. $\square$ No
If you answered YES, what diseases?

63. How often have you missed days from work in the last year? (check one answer)
$0 . \square$ None
1. $\square$ 1-2 Times
2. $\square$ 3-5 Times
3. $\square$ 6-10 Times
4. $\square$ More than 10 times

64. Do you smoke cigarettes regularly now? (check one answer)

$$
\begin{aligned}
& \text { 1. } \square \text { Yes } \\
& \text { 2. } \square \text { Ex-smoker } \\
& \text { 3. } \square \text { Never smoked }
\end{aligned}
$$

65. On average, how many cigarettes a day do you usually smoke? (check one answer)

$$
\begin{aligned}
& \text { 0. } \square \text { None } \\
& \text { 1. } \square \text { Less than } 5 \\
& \text { 2. } \square \text { Between } 5 \text { and } 15 \\
& \text { 3. } \square \text { More than } 15
\end{aligned}
$$

Next, there is a question about drinks which contain alcohol (that is, beer, wine, or other liquors like whisky, vodka, gin, or brandy). One drink is equal to a can of beer, a glass of wine, or a shot of spirits.

66. How many drinks a week have you had on average in the past year? (check one answer)

$$
\begin{aligned}
& \text { 0. } \square \text { None } \\
& \text { 1. } \square \text { 1-2 Drinks } \\
& \text { 2. } \square \text { 3-6 Drinks }
\end{aligned}
$$

\section{7-10 Drinks \\ 4. $\square$ More than 10 drinks}

67. How many aspirin (that is, tablets like Bayer Aspirin, Bufferin, Anacin, Ascriptin, Excedrin, Alka-Selter) have you take on average each week in the past year? (check one answer)

$$
\begin{aligned}
& \text { 0. } \square \text { None } \\
& \text { 1. } \square \text { 1-2 Tablets or capsules } \\
& \text { 2. } \square \text { 3-6 Tablets or capsules } \\
& \text { 3. } \square \text { 7-10 Tablets or capsules } \\
& \text { 4. } \square \text { More than } 10 \text { tablets or capsules }
\end{aligned}
$$

68. How many Tylenol or Panadol or Anacin 3 have you taken on average each week in the past year? (check one answer)

$$
\begin{aligned}
& \text { 0. } \square \text { None } \\
& \text { 1. } \square \text { 1-2 Tablets or capsules } \\
& \text { 2. } \square \text { 3-6 Tablets or capsules } \\
& \text { 3. } \square \text { 7-10 Tablets or capsules } \\
& \text { 4. } \square \text { More than } 10 \text { tablets or capsules }
\end{aligned}
$$

69. Current marital status: (check one answer)

$$
\begin{aligned}
& \text { 1. } \square \text { Married } \\
& \text { 2. } \square \text { Single } \\
& \text { 3. } \square \text { Widowed } \\
& \text { 4. } \square \text { Divorced } \\
& \text { 5. } \square \text { Separated } \\
& 6 \square \text { Other }
\end{aligned}
$$

70. Are you presently: (check one answer)

1. $\square$ Employed

2. $\square$ Unemployed

3. $\square$ Retired

4. $\square$ Full-time homemaker

Please describe the usual occupation of the principal wage earner in your household (if retired, describe the usual occupation before retirement).

Title:

Kind of Work:

Kind of Company or Business:

71. Please indicate your educational training. (check one answer)

1. $\square$ professional training beyond college

2. $\square$ College graduate (4 years)

3. $\square$ Some college

4. $\square$ High school graduate

5. 10-11 Years of school, including some high school

6. 7-9 Years of school, grade school graduate

7. $\square$ Under 7 years of grade school

Finally, please complete the following symptoms checklist

Important: For each of the symptoms or illnesses below, please indicate how often it occurred and how bothersome it was in the last year:

(Write down a number from 0 to 4 for all 17 questions in both columns.) 


\begin{tabular}{l|l}
\hline How often? & How bothersome? \\
0 - Not a problem & - - Not a problem \\
1 - Occurs about once a month & 1 - Slightly bothersome when occurs \\
2 - Occurs about once a week & 2 - Moderately bothersome when occurs \\
3 - Occurs several times a week & 3 - Severely bothersome when occurs \\
4 - Occurs daily & 4- Extremely bothersome when occurs \\
\hline
\end{tabular}

\begin{tabular}{|l|r|r|}
\hline & $\begin{array}{r}\text { How often? } \\
(0-4)\end{array}$ & $\begin{array}{r}\text { How bothersome? } \\
(0-4)\end{array}$ \\
\hline 1. Headaches & & \\
\hline 2. Backaches & & \\
\hline Stomach (gastric) or duodenal ulcer & & \\
\hline 3. Stomach pain & & \\
\hline 4. Asthma & & \\
\hline 5. Spastic colon (irritable bowel) & & \\
\hline 6. Insomnia (difficulty sleeping) & & \\
\hline 7. High blood pressure & & \\
\hline 8. Fatigue (tiredness) & & \\
\hline 9. Depression & & \\
\hline 10. Nausea & & \\
\hline 11. General stiffness & & \\
\hline 13. Heart palpitation & & \\
\hline 14. Eye pain associated with reading & & \\
\hline 15. Diarrhea/ constipation & & \\
\hline 16. Dizziness & & \\
\hline 17. Weakness & & \\
\hline
\end{tabular}

Please check that you have answered all 17 questions - every question should have a number from 0 to 4 in the "How often?" and "How bothersome?" columns.

Thank you. 


\section{Anexo - Questionário traduzido}

\section{Questionário sobre sintomas abdominais}

Primeiro, queremos fazer algumas perguntas sobre qualquer dor no estômago ou na barriga que você tenha sentido no último ano, ou seja, nos últimos 12 meses.

1.Sentiu alguma dor ou pontada na barriga no último ano?

1. $\square \mathrm{Sim}$

2. Não

(Por favor NÃO considere dores sentidas durante a menstruação)

\begin{tabular}{c|c}
\hline Em caso positivo, por favor \\
responda às perguntas abaixo
\end{tabular}$\quad \begin{gathered}\text { Caso não tenha sentido } \\
\text { nenhuma dor, passe para a } \\
\text { pergunta 22 }\end{gathered}$

Talvez seja difícil descrever uma dor no estômago ou na barriga, podendo ocorrer também mais de um tipo de dor. Pense no tipo de dor mais comum ou principal que você sente. Queremos saber somente sobre as dores no estômago ou na barriga mais comuns ou principais.

2.Você sentiu essa mesma dor ou pontada mais que seis vezes no último ano?

$$
\text { 1. } \square \mathrm{Sim}
$$

2. $\square$ Não

3. Como é essa dor normalmente? (marque apenas uma resposta)

1. $\square$ leve: consegue ignorar, se não pensar nela

2. $\square$ moderada: não consegue ignorar, mas não afeta sua rotina de vida

3. $\square$ forte: afeta sua rotina de vida

4. $\square$ muito forte: afeta muito sua rotina de vida

4. A dor pode ser principalmente na parte superior da barriga (estômago), na parte inferior da barriga ou nos dois lugares. Responda sobre a principal dor que sente.

Essa dor ou pontada na barriga geralmente é: (marque apenas uma resposta)

1. $\square$ acima do umbigo, isto é, na parte superior da bariga?

2. $\square$ abaixo do umbigo, isto é, na parte inferior da barriga?

3. $\square$ Nos dois lugares, tanto acima como abaixo do umbigo?

5.Sua dor ou pontada mais comum o acorda no meio da noite?

1. $\square$ Sim

2. N Não

6.Essa dor vai e vem periodicamente, ou seja, há períodos de pelo menos um mês em que você não sente dor e períodos de semanas ou meses em que você sente a dor?

1. $\square \mathrm{Sim}$

2. Não

7.Quantas vezes você teve essa dor no último ano? (marque apenas uma resposta)

1. $\square$ Menos de uma vez por mês

2. $\square$ Cerca de uma vez por mês

3. $\square$ Cerca de uma vez por semana

4. $\square$ Várias vezes por semana

5. $\square$ Diariamente
8.Quando a dor ocorre, quanto tempo ela dura, geralmente? (marque apenas uma resposta)

1. $\square$ Menos de 30 minutos

2. De 30 minutos a 2 horas

3. $\square$ Mais de 2 horas e até 6 horas

4. Mais de 6 horas

9.Você se lembra quando foi que essa dor apareceu pela primeira vez na sua vida? (marque apenas uma resposta)

1. $\square$ Nos últimos 6 meses

2. $\square$ De 7 meses a 1 ano atrás

3. $\square$ Mais de 1 ano e até 2 anos atrás

4. $\square$ Mais de 2 anos e até 5 anos atrás

5. $\square$ Mais de 5 anos e até 10 anos atrás

6. $\square$ Mais de 10 anos atrás

Observação: quando dizemos freqüentemente isso quer dizer mais do que $25 \%$ das vezes que a dor aparece

10.Essa dor ou pontada ocorre freqüentemente antes das refeições ou quando você está com fome?

1. $\square \operatorname{Sim}$

2. $\square$ Não

11.Essa dor ou pontada ocorre freqüentemente imediatamente após as refeições (menos de 30 minutos depois)?

1. $\square$ Sim
2. $\square$ Não

12.Essa dor ocorre freqüentemente de 30 minutos a 2 horas após as refeições? 1. $\square$ Sim

2. $\square$ Não

13.Essa dor freqüentemente melhora (é aliviada) com um arroto ? 1. $\square$ Sim

2. $\square$ Não

14.Essa dor freqüentemente melhora com a evacuação?

1. $\square$ Sim

2. $\square$ Não

15.Essa dor freqüentemente melhora se você comer?

1. $\square$ Sim

2. Não

16.Essa dor freqüentemente melhora se você tomar antiácidos (como Pepsamar, Mylanta, Maalox, hidróxido de alumínio)? (marque apenas uma resposta)

1. $\square \mathrm{Sim}$

2. $\square$ Não

3. $\square$ Não tomo antiácidos

17.Essa dor freqüentemente piora se você tomar leite ou se alimentar? 1. $\square$ Sim

2. $\square$ Não 
18.Essa dor freqüentemente piora se você ingerir bebida alcoólica, como cerveja, vinho ou outras bebidas? (marque apenas uma resposta)
1. $\square \operatorname{Sim}$
2. $\square$ Não
3. $\square$ Não bebo álcool

19. Essa dor freqüentemente passa para outro lugar além de sua barriga?

1. $\square$ Sim

2. $\square$ Não

20. Você freqüentemente evacua mais quando a dor começa?

$$
\begin{aligned}
& \text { 1. } \square \text { Sim } \\
& \text { 2. } \square \text { Não }
\end{aligned}
$$

21. Você freqüentemente tem fezes moles quando a dor começa?

$$
\text { 1. } \square \mathrm{Sim}
$$

2. $\square$ Não

22. Seus hábitos de evacuação se modificaram no último ano?

$$
\text { 1. } \square \operatorname{Sim}
$$

2. $\square$ Não

23. Como você descreveria seus hábitos normais de evacuação no último ano? (marque apenas uma resposta)
1. $\square$ Normal
2. $\square$ Tenho prisão de ventre
3. $\square$ Diarréia
4. $\square$ Alterno entre prisão de ventre e diarréia

24. Quantas evacuações você tem normalmente durante uma semana? (marque apenas uma resposta)
1. $\square 1$ ou menos
2. $\square 2$
3. $\square$ 3-4
4. $\square-8$
$5 . \square 9-12$
6. $\square$ 13-16
7. $\square$ 17-21
8. $\square$ 22-26
9. $\square$ Mais de 26

25. Você toma alguma coisa para prisão de ventre (p. ex. farelo de trigo, fibra, laxante)?

1. $\square$ Sim

2. $\square$ Não

O quê?

Com que freqüência?

26. Você já encontrou muco em suas fezes no último ano (isto é, uma substância pegajosa, branca ou esverdeada)?

$$
\begin{aligned}
& \text { 1. } \square \text { Sim } \\
& \text { 2. } \square \text { Não }
\end{aligned}
$$

27. Você freqüentemente evacua menos que 3 vezes por semana?

$$
\text { 1. } \square \text { Sim }
$$

2. $\square$ Não

28. Você freqüentemente evacua mais que 3 vezes por dia?

$$
\text { 1. } \square \text { Sim }
$$

2. $\square$ Não

29. Você freqüentemente tem que fazer força para evacuar?

1. $\square$ Sim

2. $\square$ Não
30. Suas fezes freqüentemente são moles ou aquosas?

$$
\begin{aligned}
& \text { 1. } \square \text { Sim } \\
& \text { 2. } \square \text { Não }
\end{aligned}
$$

31. Suas fezes freqüentemente são duras?

$$
\text { 1. } \square \mathrm{Sim}
$$

2. $\square$ Não

32. Após uma evacuação, você freqüentemente sente como se ainda houvesse fezes para evacuar?

$$
\begin{aligned}
& \text { 1. } \square \text { Sim } \\
& \text { 2. } \square \text { Não }
\end{aligned}
$$

33. Você freqüentemente sente necessidade urgente de esvaziar seus intestinos, obrigando-o a procurar um banheiro?

$1, \square \operatorname{Sim}$

2. $\square$ Não

34. Você encontrou algum sangue nas fezes ou no vaso sanitário no último ano?

1. $\square \operatorname{Sim}$

2. $\square$ Não

\begin{tabular}{c|c}
\hline $\begin{array}{c}\text { Se a resposta à pergunta } 34 \text { for } \operatorname{sim}, \\
\text { por favor responda às perguntas } 35 \text { a } 37\end{array}$ & $\begin{array}{c}\text { Caso não tenha encontrado sangue, } \\
\text { passe para a pergunta } 38, \text { na } \\
\text { página seguinte }\end{array}$
\end{tabular}

35. Esse sangue cobre as fezes?

1. $\square$ Sim

2. $\square$ Não

36. Esse sangue é escuro e misturado com as fezes?

1. $\square \mathrm{Sim}$

2. $\square$ Não

37. O sangue gruda no papel higiênico?

1. $\square$ Sim

2. $\square$ Não

Por favor verifique se respondeu à todas as perguntas que se aplicam a você até agora

Agora, gostaríamos de saber se você tem outras queixas.

38. Quantas vezes você sentiu vontade de vomitar (enjôo) no último ano? (marque apenas uma resposta)
$0 . \square$ Nenhuma
1. $\square$ Menos de uma vez por mês
2. $\square$ Cerca de uma vez por mês
3. $\square$ Cerca de uma vez por semana
4. $\square$ Várias vezes por semana
5. $\square$ Diariamente

39. Quantas vezes você realmente vomitou no último ano? (marque apenas uma resposta)

$0 . \square$ Nenhuma

1. $\square$ Menos de uma vez por mês

2. $\square$ Cerca de uma vez por mês

3. $\square$ Cerca de uma vez por semana

4. $\square$ Várias vezes por semana

5. $\square$ Diariamente 
40. Você freqüentemente se sente inchado ou sente sua barriga inchar?

$$
\text { 1. } \square \text { Sim }
$$

2. $\square$ Não

41. Você freqüentemente sentiu dificuldade de engolir no último ano?

1. $\square \operatorname{Sim}$

2. $\square$ Não

42. Você sentiu azia (sensação de ardência ou dor no esôfago ou na boca do estômago) no último ano? (marque apenas uma resposta)

$0 . \square$ Não

1. $\square$ Menos de um semana

2. $\square$ Várias vezes por semana

3. $\square$ Diariamente

\begin{tabular}{c|c}
\hline Se tiver sentido azia: & $\begin{array}{c}\text { Se não tiver sentido azia, passe para } \\
\text { a pergunta } 44\end{array}$ \\
\hline
\end{tabular}

43. Sua azia melhora se tomar antiácidos (como Pepsamar, Mylanta, Maalox ou hidróxido de alumínio)? (marque apenas uma resposta)

1. $\square \operatorname{Sim}$

2. $\square$ Não

3. $\square$ Não tomo antiácidos

44. Você sentiu a presença de um líquido muito azedo no fundo da garganta no último ano? (marque apenas uma resposta)

$0 . \square$ Não

1. $\square$ Menos de uma vez por mês

2. $\square$ Cerca de uma vez por mês

3. $\square$ Cerca de uma vez por semana

4. $\square$ Várias vezes por semana

5. $\square$ Diariamente

45. Você perdeu peso no último ano sem fazer dieta para emagrecer? (marque apenas uma resposta)
$0 . \square$ Não
1. $\square$ Menos que $3 \mathrm{~kg}$
2. $\square 3 \mathrm{~kg}$ ou mais

46. Como se compara seu apetite no último ano com o que era antes? (marque apenas uma resposta)

$0 . \square$ Diminuiu?

1. $\square$ Mais ou menos igual?

2. $\square$ Aumentou?

Outro importante objetivo deste estudo é conhecer seu estado de saúde anterior e as consultas que fez a médicos.

47. Você teve algum episódio de dor na barriga quando criança?

1. $\square \mathrm{Sim}$

2. $\square$ Não

48. Já tirou o apêndice?

1. $\square \mathrm{Sim}$

2. $\square$ Não

49. Já tirou a vesícula?

1. $\square \operatorname{Sim}$

2. $\square$ Não

Se respondeu sim, quando?

50. Já teve alguma úlcera estomacal (gástrica) ou duodenal?

1. $\square \operatorname{Sim}$

2. $\square$ Não

Se respondeu sim, quando?

Como foi diagnosticada (por raio $\mathrm{X}$, endoscopia)?
51. Já fez alguma operação no estômago?

1. $\square \operatorname{Sim}$

2. $\square$ Não

Se respondeu sim, quando?

Que tipo de operação?

52. Já fez alguma outra cirurgia nos intestinos ou na barriga?

1. $\square \operatorname{Sim}$

2. $\square$ Não

Se respondeu sim, quando?

Que tipo de operação?

53. Quantas vezes você foi a um médico no último ano? (marque apenas uma resposta)

0. $\square$ Nenhuma

1. $\square$ 1.-2 vezes

2. $\square$ 3-5 vezes

3. $\square$ 6-10 vezes

4. $\square$ Mais de 10 vezes

54. Se foi ao médico no último ano, foi devido a alguma dor ou pontada na barriga? 1. $\square \operatorname{Sim}$

2. $\square$ Não

\begin{tabular}{c|c}
\hline $\begin{array}{c}\text { Se a resposta a pergunta } 54 \text { for sim, } \\
\text { responda a } 55 \text { a } 57\end{array}$ & $\begin{array}{c}\text { Se a resposta for não, passe para a } \\
\text { pergunta } 58\end{array}$ \\
\hline
\end{tabular}

55. Se foi ao médico no último ano devido a alguma dor ou pontada na barriga, foi porque os sintomas eram graves ou muito graves?

1. $\square \mathrm{Sim}$

2. $\square$ Não

56. Se foi ao médico durante o último ano devido a alguma dor ou pontada na barriga, foi porque os sintomas o preocuparam muito?

1. $\square \operatorname{Sim}$

2. $\square$ Não

57. Se foi ao médico no último ano devido a alguma dor ou pontada na barriga, foi porque achou que poderia estar com uma doença grave?

$$
\begin{aligned}
& \text { 1. } \square \text { Sim } \\
& \text { 2. } \square \text { Não }
\end{aligned}
$$

58. Se foi ao médico no último ano, foi por problemas nos intestinos?

1. $\square \mathrm{Sim}$

2. $\square$ Não

59. Quantos resfriados ou gripes você teve no último ano? (marque apenas uma resposta)
$0 . \square$ Nenhum
$1 . \square 1-2$
2. $\square$ 3-5
3. $\square$ 6-10
4. Mais de 10

Por favor verifique se respondeu a todas as perguntas que se aplicam a você até agora

Para nos ajudar a interpretar os resultados desta pesquisa, gostaríamos de fazer algumas perguntas sobre suas atividades, hábitos, emprego e grau de escolaridade. Gostaríamos de lembrar que todas as informações serão mantidas sob o mais completo sigilo. 
60. Suas atividades foram interrompidas no último ano devido a dor ou pontada no estômago ou na barriga?

$$
\begin{aligned}
& \text { 1. } \square \text { Sim } \\
& \text { 2. } \square \text { Não }
\end{aligned}
$$

61. Suas atividades foram interrompidas no último ano devido a problemas intestinais?

$$
\begin{aligned}
& \text { 1. } \square \text { Sim } \\
& \text { 2. } \square \text { Não }
\end{aligned}
$$

62. Suas atividades foram interrompidas no último ano devido a outras doenças?
1. $\square \operatorname{Sim}$
2. $\square$ Não
Se respondeu sim, que doenças?

63. Com que freqüência você faltou a escola no último ano?

$0 . \square$ Nenhuma vez

1. $\square$ 1-2 vezes

2. $\square$ 3-5 vezes

3. $\square$ 6-10 vezes

4. $\square$ Mais de 10 vezes

64. No momento, você fuma cigarros regularmente? (marque apenas uma resposta)
1. $\square \operatorname{Sim}$
2. $\square$ Não
3. $\square$ Nunca fumei

65. Quantos cigarros, em média, você normalmente fuma por dia? (marque apenas uma resposta)

$0 . \square$ Nenhum

1. $\square$ Menos de 5

2. $\square$ Entre 5 e 15

3. $\square$ Mais de 15

A próxima pergunta é sobre ingestão de bebidas que contêm álcool (isto é, cerveja, vinho, cachaça, uísque, vodca, gim ou conhaque). Um drinque é igual a uma latinha de cerveja, uma taça de vinho ou uma dose de bebida destilada.

66. Quantos drinques, em média, você tomou por semana no último ano? (marque apenas uma resposta)

$0 . \square$ Nenhum

1. $\square$ 1-2 drinques

2. $\square$ 3-6 drinques

3. $\square$ 7-10 drinques

4. $\square$ Mais de 10 drinques

67. Quantas aspirinas (isto é, comprimidos como Aspirina, Bufferin, AAS, Melhoral), em média, você tomou por semana no último ano? (marque apenas uma resposta)

$0 . \square$ Nenhuma

1. $\square$ 1-2 comprimidos ou cápsulas

2. $\square$ 3-6 comprimidos ou cápsulas

3. 7-10 comprimidos ou cápsulas

4. $\square$ Mais de 10 comprimidos ou cápsulas

68. Quantos Tylenol, Dôrico, ou Paracetamol, em média, você tomou por semana no último ano? (marque apenas uma resposta)

$0 . \square$ Nenhum

1. $\square$ 1-2 comprimidos ou cápsulas

2. 3-6 comprimidos ou cápsulas

3. 7-10 comprimidos ou cápsulas

4. $\square$ Mais de 10 comprimidos ou cápsulas
69. Sexo:

$$
\begin{aligned}
& \text { 1. } \square \text { Masculino } \\
& \text { 2. } \square \text { Feminino }
\end{aligned}
$$

70. Sua idade atual:

1. $\square 14$ anos

2. $\square 15$ anos

3. $\square 16$ anos

4. $\square 17$ anos

5. $\square 18$ anos

6. $\square$ Mais de 18 anos

71. Agora gostaríamos de obter algumas informações sobre o trabalho da pessoa que sustenta sua casa (se for aposentado, descreva sua função principal antes da aposentadoria).

Profissão:

Tipo de Trabalho:

Local onde trabalha:

Finalmente, por favor preencha a lista de sintomas abaixo

Atenção: Indique, para cada sintoma ou doença abaixo, a freqüência com que ocorre e o quanto o incomodou durante o último ano.

(marque de 0 a 4 em todas as 17 perguntas abaixo em ambas as colunas.)

\begin{tabular}{l|c}
\hline Com que freqüência? & Com que grau de incômodo? \\
0 - não foi problema & 0 - não foi problema \\
4 - ocorre mais ou menos 1 & 1 - ligeiro incômodo \\
vez por mês & quando ocorre \\
5 - ocorre mais ou menos 1 & 2 - incômodo moderado \\
vez por semana & quando ocorre \\
6 - ocorre várias vezes & 3 - incômodo forte quando ocorre \\
por semana & 4 - extremo incômodo \\
7 - ocorre todos os dias & quando ocorre \\
\hline
\end{tabular}

\begin{tabular}{|l|l|l|}
\hline & $\begin{array}{c}\text { Com que } \\
\text { freqüência? (0-4) }\end{array}$ & $\begin{array}{c}\text { Com que grau de } \\
\text { incômodo? (0-4) }\end{array}$ \\
\hline 1. Dor de cabeça & & \\
\hline 2. Dor nas costas & & \\
\hline $\begin{array}{l}\text { 3. Úlcera estomacal (gástrica) } \\
\text { ou duodenal }\end{array}$ & & \\
\hline 4. Dores na barriga & & \\
\hline 5. Asma & & \\
\hline 6. Cólon irritável & & \\
\hline $\begin{array}{l}\text { 7. Insônia (dificuldade de } \\
\text { dormir) }\end{array}$ & & \\
\hline 8. Pressão alta & & \\
\hline 9. Fadiga (cansaço) & & \\
\hline 10. Depressão & & \\
\hline 11. Enjôo & & \\
\hline 12. Palpitação no coração & & \\
\hline $\begin{array}{l}\text { 13. Dor nos olhos relacionada } \\
\text { à leitura }\end{array}$ & & \\
\hline 14. Prisão de ventre & & \\
\hline 15. Diarréia & & \\
\hline 3. Tontura & & \\
\hline 4. Fraqueza & & \\
\hline
\end{tabular}

Por favor verifique se respondeu as 17 perguntas - todas devem ter um número de 0 a 4 nas colunas "Com que freqüência?" e "Com que grau de incômodo?"

Obrigado 